\title{
Protection, Regulation and Identity of Cultural Heritage: From Sign-Meaning to Cultural Mediation
}

\author{
Anne Wagner ${ }^{1} \cdot$ Aleksandra Matulewska $^{2}$ (D) Cheng Le $^{3}$
}

Accepted: 4 February 2021 / Published online: 8 March 2021

(c) The Author(s), under exclusive licence to Springer Nature B.V. part of Springer Nature 2021

\begin{abstract}
In our research project, we will elaborate Charles Sanders Peirce's three philosophical categories, and show how these categories operate at the levels of Protection, Regulation and Identity in the process of sign-meaning and sign-making within Cultural Heritage, Law and Discourse. The process of semiosis comprises a triadic dimension between signs, their functions and interpretations, operating on four axes within our special issue: Theoretical Cultural Heritage Issue (1st axis), Cultural Heritage and Postcolonialism (2nd axis), Intertwined Notions of Heritage and Culture (3rd axis), and Protection of Cultural Heritage (4th axis).
\end{abstract}

Keywords Law $\cdot$ Cultural heritage $\cdot$ Culture $\cdot$ History $\cdot$ Identity $\cdot$ Conservation Protection $\cdot$ Regulation

Cultural heritage undergoes a continuous process of evolution.

(Heritage and Society [5 p. 145]

[...] Cultural heritage is just as much about the present and the future: about how culture is embroiled in contemporary moral controversies, and about what our cultural legacy will be.

(Matthes Fall [7], Introduction)

Aleksandra Matulewska

aleksandra.matulewska@gmail.com

Anne Wagner

valwagnerfr@yahoo.com

Cheng Le

chengle163@hotmail.com

1 ULR 4487 - CRDP - Centre de recherche Droits et perspectives du droit, University of Lille, Équipe René Demogue, France

2 Faculty of Modern Languages and Literatures, Adam Mickiewicz University, Collegium Novum, al. Niepodległości 4, Block A Room 107, 61-874 Poznan, Poland

3 Institute of Cross-Cultural and Regional Studies, School of International Studies, Zhejiang University, Hangzhou, China 


\section{Introduction}

The last four decades have witnessed the remarkable extension of enthusiasm in cultural heritage or property from the perspective of international laws, or international legal framework, such as the multilevel legal instruments for safeguarding, protection and maintenance of cultural heritage, property, or rights. In our project, the identification of "cultural heritage" employs specific discourses, codes, transcending values, and images that conceal assumption about members of a people comprising a people within a nation. Cultural heritage narrates constructions of belongings that become tethered to negotiations for power and resistance over time and throughout a people's history leading to powerful discursive narratives. While such likeness may be preserved, conserved or even perpetuated, the idea of "cultural heritage" may be socially, politically, culturally, and historically contested to reveal competing pasts, presents, and futures, esp. with innovation in arts leading to new social norms and identities. One of such innovations is digital culture and the notion of digital cultural heritage. Besides, the visual decoding of heritage is evocative and ideologically representative with meanings that prescribe a story of Protection, Regulation and Identity, since these meanings are subject to multiple interpretations and reinterpretations related to Rights, among the integrity of heritage right and human rights, and the integrated framework of right in rem and right in personae. However, the interpretations of cultural heritage are far from being objective. It can be clearly seen from the analysis of discussions whether some tangible or intangible cultural object should be protected or not, that the protection of diversity and tolerance are far from the postulated ideal.

"Beyond the traditional psychological concentration on mental structures and functions 'inside' an individual it considers the personal appropriation of signs by persons within their social contexts of learning and signing. Beyond behavioural performance this viewpoint also concerns patterns of sign use and production, including individual creativity in sign use, and the underlying social rules, meanings and contexts of sign use as internalized and deployed by individuals" [4: p. 68].

The competing and conflicting interests of communities, who want to protect their cultural heritage and communities and appropriate or even destroy them, collide. The story of Aalast festival and its appearance and disappearance from the UNESCO heritage list may serve as an example here. Yet, through semiotic accumulation, evolution and confrontation, there may be different interdisciplinary paths leading to different truths, to tensions (contestation and/or negotiation), and applications of significance. We should then investigate these transmitted values, discourses over time and space:

"Heritage is no longer cold stones or the glass separating us from exhibits in a museum. It is also the village lavoir, the little country church, local dialects, the charm of family photos, skills and techniques, language, written and oral tradition, humble architectures [...] Cultural heritage embraces everything that human effort has left us during the course of history, music, dance and song, literature 
and folk customs, paintings and archives - in short, everything that bears witness to humanity down the path of time" (French Minister for Culture and Communication Jean-Philippe Lecat quoted in [6: p. 211]).

Accordingly, heritage is a process not only of sign-meaning and sign-making but also of sign-confrontation, which needs cultural mediation-i.e. "cultural process" [8].

A cultural process that engages with acts of remembering that work to create ways to understand and engage with the present, and the sites themselves are cultural tools that can facilitate, but are not necessarily vital, for this process [8: p. 44].

In this special issue, the authors focus on theoretical problems of transmitting and protecting cultural heritage. They highlight a social stratification in transmitting, preserving and conserving cultural heritage among others, showing that liberalism and communitarianism are frequently exclusive. The second group of papers, focusing on heritage and postcolonialism, deals with the right for the preservation and conservation of a people's memory and legal frameworks at national and international levels enabling or hindering such protection. The third category of papers is devoted to the notions of heritage and culture and their evolution. The authors aim at answering the question: How cultural heritage is interpreted within legal settings or international legal framework from temporality and spatiality? The last four papers focus on the problems connected with the transmission of heritage and the interactions between cultural heritage and human rights within the diversity and tolerance within socio-legal contexts. As it turns out the new narratives are created by communities to diminish the value of some types of heritage despite their collective and cultural values. The narratives are far from being objective and frequently deny the tangible and intangible heritage the right for protection solely on the grounds of being contrary to modern life styles. The cognitive and symbolic aspects of Cultural heritage pervading through different temporal and spatial parameters are disregarded or even boycotted. This shift in understanding and interpreting cultural heritage from one space to another leads to censorship of some types of heritage. Therefore, the question may be posed about the relationship between law and "heritage" (tangible or intangible elements) and the role of law in protection of cultural heritage. In an objective way, it may be preserved for future generations that may follow a different path of assessing the shared collective and/or cultural memory of their predecessors.

\section{Theoretical Cultural Heritage Issues}

The first three papers open the theoretical plane for discussing the interaction between cultural heritage and law. Marta Andruszkiewicz in her paper titled The Heritage of Cultural Determinants of Law and Literature: Methodological Findings focuses on the cultural studies and its impact on the domain of law. The author stresses the interdisciplinary nature of contemporary research in many fields. The cultural studies affect nowadays significantly the philosophy of law and legal practice. It can be seen through the prism of text interpretation and legal discourse analysis. Law is perceived as a culture-bound object shaped by society in a variety of ways. As a consequence, the role of a lawyer is undergoing changes as well. The 
heritage of cultural determinants of law and literature cannot be ignored as they affect the methodologies of law and philosophy of law in a visible way. MarieSophie de Clippelle in her paper Does the Law Determine What Heritage to Remember? Tackles the problem of heritage, memory and totalitarianism. The author investigates the role of cultural heritage and its preservation in a memory of a nation. Issues of political tampering, ideological manipulation and changing memories are discussed. Clippelle claims that the question may be posed "who gets to decide what is considered heritage according to the law, and whether there is something such as a collective human right to cultural heritage." This question is present explicitly and implicitly in other papers published in this volume, just to mention the contributions from (i) Zeidler and Łagiewska, (ii) Dajczak, Gwiazdowicz, Matulewska and Szafrański, and (iii) Svetlicinii. These papers also investigate the issue from various perspectives indicating that it is very easy nowadays to forget what the UNESCO stresses as an intangible element of culture, which "can only be heritage when it is recognized as such by the communities, groups or individuals that create, maintain and transmit it - without their recognition, nobody else can decide for them that a given expression or practice is their heritage". ${ }^{1}$ However, contemporary societies, which promote tolerance for heritage, do it only superficially and at the same time they deny the right to the protection of heritage, which they do not consider compliant with their interests (including political, ideological and financial ones), way or even style of living. Kamil Zeidler and Łagiewska Magdalena in their paper Liberalism versus Communitarianism in Cultural Heritage Law discuss the important issue of heritage, preservation and rights to tangible property considered heritage. The competing interests of communities and individuals sometimes generate conflicts of interests. The authors pose a question whether an individual or a community have a right to destroy a piece of art considered cultural heritage. This ongoing battle between liberalism and communitarianism in cultural heritage law calls for new legal solutions which will provide the protection of heritage irrespective of particular interests of political, social or other nature of both individuals and communities. Indeed, cultural heritage is the shared collective and/or cultural memory that should be preserved. Additionally, cultural heritage is connected to the preservation and conservation of a people's memory. And even if we do not accept it socially or politically, it does not diminish its historical value.

\section{Cultural Heritage and Postcolonialism}

Three papers focus on the issue of cultural heritage in postcolonial reality. No one can deny that many nations lost numerous objects of tangible heritage, and were hence deprived of their intangible heritage by colonialists. Miroslaw Sadowski, who contributed the paper entitled Mapping the Art Trade in South East-Asia: From Source Countries via Free Ports to (a Chance for) Restitution, addresses one of the

\footnotetext{
1 UNESCO, What is intangible cultural heritage? https://ich.unesco.org/en/what-is-intangible-heritage00003 .
} 
issues directly resulting from the consequences of colonialism that is to say trafficking in works of art in the South East Asia. After highlighting the major events in the history of illicit antiquities trade and international legal provisions in this respect, he provides some valuable insight into the methods of smuggling works of art from the country of origin to the port of first shipment. Then, he presents the specificity of the Hong-Kong law, which facilitates obtaining cultural objects in good faith and depriving lawful owners of the right to have them restituted. Finally, the conclusions are drawn in respect to possibilities of curtailing the works-of-art trafficking. Gerlov, Engelenhoven in his paper From Indigenous Customary Law to Diasporic Cultural Heritage: Reappropriation of Adat Throughout the History of Moluccan Postcolonial Migration focuses on the evolution of the meaning of the term adat that "as a form of diasporic cultural heritage by the Moluccan postcolonial migrant community in the Netherlands". In fact, the case of the Moluccan separatists and their approach to Indonesia is considered here as the protection of collective memory and identity. The paper addresses Human Rights. The question arising here is whether all ideologies should be protected and what should be the limits of the diversity and tolerance within socio-legal contexts. The last paper focusing on colonialism and postcolonialism has been written by Noelle Higgins. It is titled Songlines and Land Claims, Space and Place. These narratives are recognised as the symbols of land ownership and are used in claims concerning titles to land. The author focuses on the value of Songlines as court evidence that may be used in legal proceedings to recover the land in postcolonial era where indigenous people are recognized as victims of colonialists.

\section{The Intertwined Notions of Heritage and Culture}

The next four papers provide an insight into the notion of cultural heritage and its evolution. Sabrina Ferrazzi contributed the paper titled The Notion of "Cultural Heritage" in the International Field: Behind Origin and Evolution of a Concept. First, the author scrutinizes the notion of culture and its understanding, and then provides the analysis of the term cultural heritage. Both terms are vague and do not have precise meanings. Their interpretations depend on temporal and spatial factors. Additionally, interpretative problems are enhanced by the terminologies used in legal instruments, such as 1954 Hague Convention, 1970 UNESCO Convention, and 1972 World Heritage Convention. Ferrazzi discusses communitarianism and territorialism in cultural heritage legal discourse revealing a wide array of possible interpretations of the term in question. The impact of social and legal factors is highlighted. The understanding of the term affects the transmission of heritage and its protection. Dario Haux (A Cultural Memory of the Digital Age?) also deals with the meaning of the term culture and new forms of it, that is to say, digital culture and digital cultural heritage. The new technologies, evolving in an extremely dynamic way at the turn of the twenty-first century create a new space of expression and sharing of all sorts of information including cultural one via words and images. The author focuses on setting 'the criteria for defining heritage in memory theoretization ... and to give Aleida and Jan Assmann's Theory of Cultural Memory a normative 
dimension". The new digital spaces in which culture is created and functions are definitely end up replacing the old culture transmission media and becoming new storing spaces for cultural heritage of modern societies. The following paper from Yulia Erokhina (Semiotic Interpretation of the Sign 'Ecclesiastical Court' Within the Framework of legal Precepts in Terms of Temporality and Spatiality (Case of Russia)) focuses on spatial and temporal factors of the interpretation of the term Ecclesiastical Court. She provides and insight into the cognitive and symbolic aspects of the sign through different temporal parameters deeply rooted in the history of Russian society. She discusses the shift in cultural and/or collective meaning of the term in question that actually emerged as a result of the symbolic meaning given to the term by F. M. Dostoevsky in his novel The Brothers Karamazov, which broadened the legal meaning significantly. The sign has therefore numerous dimensions starting with the legal one, through spiritual, sensual and ending with the metaphorical one. As the author claims that "several semantically heterogeneous meanings of the sign of Ecclesiastical Court are revealed and described" in the paper.

\section{Protection of Cultural Heritage and Rights to Heritage}

In this section, the authors focus on the problems of cultural heritage protection. As already indicated in the paper by Zeidler and Łagiewska, liberalism and communitarianism wage a war as far as the protection of cultural heritage is concerned. These opposing interests very frequently make it impossible to protect tangible and intangible values. This sensitive issue is also highlighted by Wojciech Dajczak, Dariusz J. Gwiazdowicz, Aleksandra Matulewska and Wojciech Szafrański in their paper Should Hunting as a Cultural Heritage Be Protected? The authors focus on the heritage of hunting, which in the contemporary world is perceived stereotypically and is condemned by various groups starting from vegetarians and ending with some scholars in animal studies and environmentalists. The legal reasonability test is applied to provide some insight into the analysis of hunting in the context of its cultural heritage and its impact on environment. The issue of stereotypical perception of hunting as a blood sport or recreational sport is uncovered. It is argued that modern hunting has evolved and does not serve recreational purposes, but rather to solve unavoidable human-wildlife conflicts, being hard to avoid in urbanized Europe. The paper focuses on the interactions between cultural heritage and human rights within the diversity and tolerance under socio-legal perspectives. It transpires that in cultural heritage hunting, acceptance of diversity and tolerance are nothing more than empty words. The next paper by Alexandr Svetlicinii titled Cultural Heritage Divided by (International) Law: the Case of North Macedonia deals with an extremely important issue of the battle over the rights to ethnic group heritage - the battle of the weakest against the strongest. The article touches upon a very interesting issue of mingling politics with heritage of peoples and the influence of larger nations over smaller ones. The problems discussed open a new plane for a debate on rights to heritage recognition and protection. The case for the Macedonian nation's struggle for the recognition of its rights to a secular heritage, having an intercultural dimension, deserves consideration when amending heritage laws with a view to 
preventing inequalities and discriminatory activities of stronger nations. The conclusion is that heritage laws should be objective and should prevent from being granted solely on the basis of political pressure. As intercultural contacts and the impact of one culture on another are increasingly being debated, one may expect an increase in tangible and intangible cultural heritage in the era of globalisation and the growth of mixed ethnic groups seeking its preservation and its international recognition. Another paper on the issue of which cultural heritage deserves protection and which should be deprived of it is written by Luminita Oletanu (Riding on the Coat-Tails of Traditional Cultural Expressions). The author discusses traditional cultural expressions ('TCEs') and expressions of folklore ('EoFs'), the problem of establishing their owners and the need for their legal protection in the European contexts. To illustrate the analysis, the trade mark legislation is taken as an example. Oletanu claims that the "article advances the thesis that registration of TCEs and EoFs as trademarks generates an imbalance between the rights of the trade mark owner and the defences available to others under the EU trade mark law framework. Furthermore, such an imbalance is likely to hinder the unfettered circulation of TCEs and undermine their original meaning. Lastly, in some cases, trade mark registration of TCEs contributes to their appropriation and misappropriation." Le Cheng and Yuchang Yuan, who wrote Intellectual Property Tools in Safeguarding Intangible Cultural Heritage: A Chinese Perspective, focuses on the gaps in legislation. The authors provide a valuable insight into intellectual property (IP) being considered intangible cultural heritage, and the history of its protection in China. The evolution of the Chinese intellectual protection laws and solutions are provided. Finally, the authors formulate some recommendations concerning the amendments of provisions on the protection of IP based on the analysis of other legal systems in this respect. The paper So Close and Yet so Far: The Distant Heritage of the Historical Urban Landscapes of Residential Districts of Tartu, Estonia by Kadri Kallast focuses on historical values of city centres. The need for making citizens aware of the value of local historical urban landscapes is highlighted. The inhabitants who are not aware of the value of buildings in which they live, frequently not only fail to appreciate the buildings but also contribute to diminishing their value by mistreatment. Making communities appreciate the urban landscapes that date back to the late nineteenth and early twentieth centuries could contribute to the better understanding of renovation and construction restrictions. In order to achieve that aim, the authorities should modify the public discourse in this respect to form a bond between inhabitants of historical urban landscapes and the buildings in which they live.

\section{Conclusions}

Considering the complexity and diversity in the building of a common memory or discourse community through tangible and intangible cultural heritage, one needs to stress that tolerance and preservation of diversity are of utmost importance. Therefore, the triadic dimension of Cultural Heritage, Law and Discourse relates to an "endless flux of interlocking events continuously going on in the world and being 
carried out more or less consciously" [1: p. 49]. It can then be easily connected to the Deleuze and Guattary theory of the rhizome, which allows that:

A rhizome has no beginning or end; it is always in the middle, between things, interbeing, intermezzo. The tree is filiation, but the rhizome is alliance, uniquely alliance. The tree imposes the verb 'to be', but the fabric of the rhizome is the conjunction, 'and ... and ... and ... [2: p. 27].

Bennett [1] adds a valuable dimension to sign-system constructions by stating that a system is: "a set of independent but mutually relevant terms, in which term refers to those elements of the system that express a specific character, such as universality, complementarity, dynamism, activity, potential, and so forth" [1: p. 13].

Accordingly, the complex sign systems of a particular country or region and their meanings attentive to a complex configuration of historical, social and cultural conditions that shift over time and space should be recorded and preserved for future generations. Deleuze and Guattari distinguish two types of possession deriving from the rhizome theory, and easily applicable to the notions of cultural heritage - a fixed versus an evolving concept, claiming the first one is territorialised while the second one is deterritorialised. The first concept-being tangible-depends on regulations, property rights and legislations in defined territories and jurisdictions [10, 11] World Heritage list website), while the second concept - being intangible - is more about transnational traditions worldwide (Unesco, 17 Dec. 2020). However, both concepts may intertwin and connect together (Deleuze and Guattari), and lead to new "cultural routes" defined as:

A land, water, mixed or other type of route, which is physically determined and characterized by having its own specific and historic dynamics and functionality, showing interactive movements of people as well as multi-dimensional, continuous and reciprocal exchanges of goods, ideas, knowledge and values within or between countries and regions over significant periods of time, and thereby generating a cross-fertilization of the cultures in space and time, which is reflected both in its tangible and intangible heritage [3: p. 11].

Modern societies condemn decisions of governments of various countries to destroy the heritage that was not politically correct at some point in time. The present generation perceives such acts of destruction as cultural atrocities. So, the rationale of our Special Issue is to highlight the variable degrees of cultural heritage, being the Unesco's Peace Mandate to facilitate the transmission of history:

UNESCO must meet the immense challenge of uniting peoples on an unprecedented scale in order to pave a path towards peace. Our common heritage is poignantly revealed in some of the most tragic events of human history (Unesco, Culture World Heritage, see website).

\section{References}

1. Bennett, J.G. 1993. Elementary Systematics: A Tool for Understanding Wholes. New-York: Bennett Books.

2. Deleuze, Gilles, and Félix. Guattari. 2011. A Thousand Plateaus: Capitalism and Schizophrenia. London: Athlone. 
3. Durusoy, Elifnaz. 2014. From An Ancient Road to A Cultural Route. Istanbul: Institut Français d'études anatoliennes.

4. Ernest, P. 2006. A Semiotic Perspective of Mathematical Activity: The Case of Number. Educational Studies in Mathematics 61: 67-101.

5. Heritage and Society. 2015. Nara + 20: On Heritage Practices, Cultural Values, and the Concept of Authenticity. Heritage and Society 8 (2): 144-147.

6. Loulanski, Tolina. 2006. Revising the Concept for Cultural Heritage: The Argument for a Functional Approach. International Journal of Cultural Property. 13 (2): 207-233.

7. Matthes Erich Hatala. Fall 2018 Edition. The Ethics of Cultural Heritage. The Stanford Encyclopedia of Philosophy. Edward N. Zalta (ed). https://plato.stanford.edu/archives/fall2018/entries/ethic s-cultural-heritage. Accessed on 22 January 2021.

8. Laurajane, Smith. 2006. The Uses of Heritage. New York: Routledge.

9. Unesco. 17 December 2020. UNESCO Assembles Peoples Around Transnational Traditions Like Couscous, One of 32 New Inscriptions on its Intangible Heritage Lists. https://ich.unesco.org/en/ news/unesco-assembles-peoples-around-transnational-traditions-like-couscous-one-of-32-new-inscr iptions-on-its-intangible-heritage-lists-13288. Accessed on 18 January 2021.

10. Unesco. World Heritage List. https://whc.unesco.org/en/list/. Accessed on 18 January 2021.

11. Unesco. World Heritage at the Heart of UNESCO'S Peace Mandate. http://www.unesco.org/new/en/ culture/resources/in-focus-articles/heritage-and-peace/. Accessed on 18 January 2021.

Publisher's Note Springer Nature remains neutral with regard to jurisdictional claims in published maps and institutional affiliations. 